This item was submitted to Loughborough's Research Repository by the author.

Items in Figshare are protected by copyright, with all rights reserved, unless otherwise indicated.

\title{
Dynamic modelling and nonlinear model predictive control of a fluid catalytic cracking unit
}

PLEASE CITE THE PUBLISHED VERSION

\section{PUBLISHER}

(C) Elsevier

\section{VERSION}

AM (Accepted Manuscript)

\section{LICENCE}

CC BY-NC-ND 4.0

\section{REPOSITORY RECORD}

Roman, Raluca, Zoltan K. Nagy, Mircea V. Cristea, and Serban P. Agachi. 2009. "Dynamic Modelling and Nonlinear Model Predictive Control of a Fluid Catalytic Cracking Unit”. figshare.

https://hdl.handle.net/2134/4991. 
This item was submitted to Loughborough's Institutional Repository (https://dspace.lboro.ac.uk/) by the author and is made available under the following Creative Commons Licence conditions.

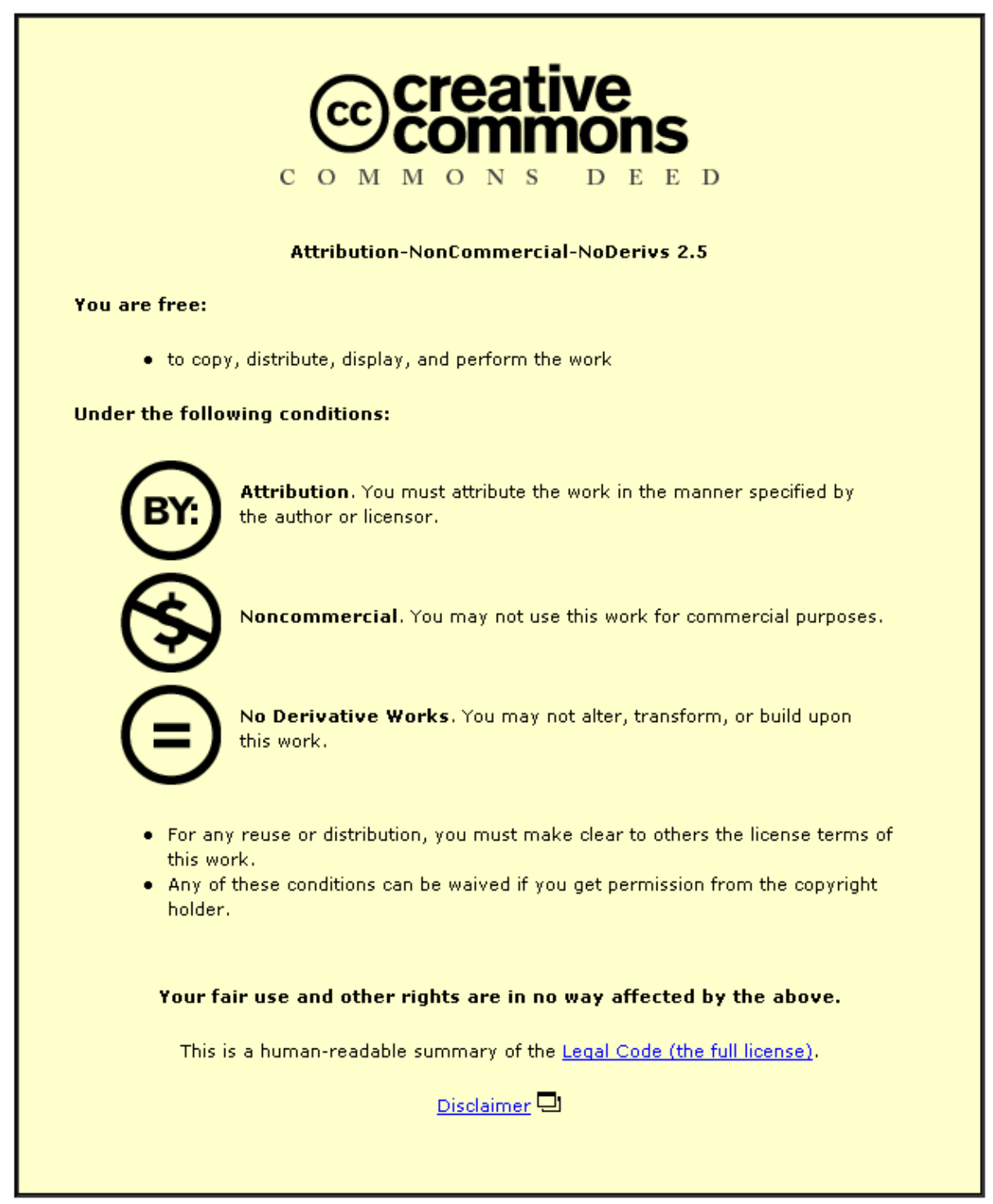

For the full text of this licence, please go to: http://creativecommons.org/licenses/by-nc-nd/2.5/ 


\title{
Dynamic Modelling and Nonlinear Model Predictive Control of a Fluid Catalytic Cracking Unit
}

\author{
Raluca Roman $^{\mathrm{a}}$, Zoltan K. Nagy ${ }^{\mathrm{b}}$, Mircea V. Cristea ${ }^{\mathrm{a}}$, Serban P. Agachi ${ }^{\mathrm{a}}$ \\ aDepartment of Chemical Engineering, "Babes-Bolyai” University, \\ 11 Arany Janos, Cluj-Napoca, 400028, Romania \\ ${ }^{\mathrm{b}}$ Department of Chemical Engineering, Loughborough University, \\ LE11 3TU, Loughborough, United Kingdom
}

\begin{abstract}
The paper presents the application of two nonlinear model predictive control (NMPC) approaches: quasi-infinite horizon nonlinear MPC (QIHNMPC) and moving horizon estimator nonlinear MPC (MHENMPC) to the FCCU. A complex dynamic model of the reactor-regenerator-fractionator system is developed and subsequently used in the controller. The novelty of the model consists in that besides the complex dynamics of the reactor-regenerator system, it also includes the dynamic model of the fractionator, as well as a five lumps kinetic model for the riser. Tight control is achieved using the QIHNMPC NMPC approach. The MHE-NMPC considers important features of a real-time control algorithm, resulting in a framework for practical NMPC implementation, such as: state and parameter estimation and efficient solution of the optimisation problem. In the NMPC approach, only measurements available in practice are considered, whereas the rest of the states are estimated together with uncertain model parameters, via MHE technique. Using an efficient numerical implementation based on the multiple shooting algorithm real-time feasibility of the approach is achieved. The incentives of the proposed approaches are assessed on the simulated industrial FCCU.
\end{abstract}

Keywords: catalytic cracking, dynamic modelling, nonlinear model predictive control, moving horizon estimator, real-time control

\footnotetext{
* Author to whom correspondence should be addressed: z.k.nagy@lboro.ac.uk
} 


\section{Introduction}

Fluid Catalytic Cracking Unit (FCCU) is one of the most important processes in a refinery, because its main product is the high quality gasoline. This process converts high molecular-weight gas oils into significantly more valuable, lighter hydrocarbon products. The process is multivariable, strongly nonlinear, highly interactive, and is subject to many operational, safety and environmental constraints, posing challenging control problems. The competitive nature of the petrochemical industries drives the constant technological development of FCC processes, with the clear economic objective of improving productivity, while maintaining safety and environmental regulations. Due to its complexity, the modelling and control of FCCU raises important challenges (McFarlane et al., 1993, Cristea et al., 2003). FCCU has become in the last decades the testing bench for many modern refinery control systems. This chemical process has been traditionally controlled using algorithms based on a linear time-(in)variant approximate process model, the most common being step and impulse response models derived from the convolution integral. Linear model predictive control has proved its benefits in the petrochemical industries in the past two decades, but nonlinear model predictive control (NMPC) has the potential to achieve higher productivity by exploiting the advantages of taking process nonlinearities explicitly into account (Qin and Badgewell, 2003). However, the application of NMPC requires models with good prediction quality. With the increase of computing power and the development of modern optimisation and model reduction algorithms recently there has been a growing emphasis on the control of complex continuous and batch chemical processes (Baldea et al., 2006; Engell, 2007; Skogestad, 2004; Araujo et al., 2007; Nagy and Braatz, 2003).

The present paper presents the simulation results obtained with a complex dynamic model of the FCCU. The developed model simulates the dynamic behaviour of the reactor-regeneratorfractionator system and predicts the composition of the main products (gasoline and diesel). The composition of the main products is controlled in an inferential NMPC control scheme, based on the complex high-order nonlinear model. The advantages of a modern NMPC approach, the so-called quasi-infinite-horizon nonlinear model predictive control (QIHNMPC) and moving horizon estimator 
nonlinear MPC (MHE-NMPC) are shown to achieve better control performance, however with increased computational load. Based on a multiple shooting technique, efficient solution of the on-line optimisation is obtained even for the case of the high dimensional model.

The paper is structured as follows: Section 2 consists in the description of the plant and presents the simulation results obtained with the developed model. Section 3 describes the NMPC approaches and the related solution of the optimisation problem, together with the simulation results. Conclusions are presented in Section 4.

\section{Dynamic Modelling of the FCCU}

\subsection{Description of the system}

The schematic diagram of the FCCU, for which the mathematical model was developed and the assessment of the NMPC has been performed, is presented in Figure 1.

Figure 1. FCCU plant

Pre-heated feed is mixed with the hot slurry recycle (from the bottom of the main fractionator) and injected into the reactor riser, where it mixes with hot regenerated catalyst and totally vaporizes. As a result of the cracking reactions the main products are obtained and a carbonaceous material (coke) is deposited on the surface of the catalyst. Separation of the catalyst and gas occurs in the disengaging zone of the reactor. Entrained catalyst is removed in cyclones. Catalyst is returned to the stripping section of the reactor where steam is injected for removing entrained hydrocarbons. Since coke poisons the catalyst, continuous regeneration is required. Spent catalyst is transported from the reactor to the regenerator. Air is injected into the bottom of the regenerator. Catalyst in the regenerator is fluidized by the injected air; carbon and hydrogen on the catalyst react with oxygen to produce CO, $\mathrm{CO}_{2}$ and $\mathrm{H}_{2} \mathrm{O}$. Gas travels up in the regenerator into the cyclones where the entrained catalyst is removed and returned into fluidized bed. The regenerated catalyst returns to the reactor riser where is 
mixed with the raw material and the process starts again. Reactor products (gases, gasoline, diesel, slurry) are passed to the main fractionator for further separation (Sadeghbeigi, 2000).

\subsection{FCCU model}

The FCCU model has been developed based on reference construction and operation data from an industrial unit. The developed dynamic simulator consists of detailed models of the feed and preheats system, reactor riser and stripper, regenerator, air blower, wet gas compressor, catalyst circulation lines and main fractionator. Three fresh feeds are available to the FCCU system: gas-oil from tankage, wash oil and diesel. The sum of these flows represents the total fresh feedrate. Slurry recycle from the bottom of the main fractionator is added to the fresh feed stream after the preheating furnace.

The feed system model neglects the rapid dynamics of the flow control loops and consequently, the flow streams and actual flows are equal to the controller setpoints at all times. The furnace firebox temperature and outlet temperature from the preheat system are modelled based on the dynamic heat balance.

Reactor is divided in two parts, the riser and the stripper. The reactor riser is simulated as a diluted solid phase transport line, in which hot catalyst from the regenerator mixes with feed oil from the preheat system and recycle oil (slurry) from the main fractionator. The hot catalyst provides sensible heat, heat of vaporization and heat of reaction for the endothermic cracking reactions. All of the cracking reactions are assumed to occur only in the reactor riser. The yield of coke deposited on the catalyst in the riser is assumed to be influenced by the weight hourly space velocity in the riser, the concentration of carbon on regenerated catalyst, the catalyst residence time in the riser and the coking characteristics of the various feeds. The coke balance includes the carbon entering the reactor with regenerated catalyst. The riser energy balance assumes plug flow dynamics, with negligible heat loss to the environment. The heat of cracking is assumed proportional to the riser temperature. A constant temperature drop across the reactor stripper is assumed. The pressure at the bottom of the reactor riser and the inventory of catalyst in the riser are also modelled. A five lump kinetic model (schematically shown in Figure 2) that predicts the yield of valuable products is proposed and included in the 
simulator (Dupain et al. 2003). The plug flow riser model was simulated by dividing it in a series of 160 continuous stirred tank reactors (CSTR). For each of these CSTRs, the following assumptions have been made: less $10 \%$ of the raw material is uncrackable; effectively no gasoline overcracking takes place; diesel only cracks to gas and is not converted into gasoline.

Figure 2. Five lump model for the catalytic cracking

The rates of change in concentration for the five considered pseudocomponents are described by the equations:

$$
\begin{aligned}
& \frac{d y_{\text {oil }}}{d t}=\left(-\left(k_{1}+k_{2}+k_{3}\right)\left(y_{\text {oil }}-x_{\text {oil }}\right) \psi_{\text {conv }}-k_{5}\left(y_{\text {oil }}-x_{\text {oil }}\right) \psi_{\text {coke }}\right) C T O \\
& \left.\frac{d y_{\text {diesel }}}{d t}=\left(k_{1}\left(y_{\text {oil }}-x_{\text {oil }}\right)-k_{4} y_{\text {diesel }}\right) \psi_{\text {conv }}-k_{6} y_{\text {diesel }} \psi_{\text {coke }}\right) C T O \\
& \frac{d y_{\text {gasoline }}}{d t}=k_{2}\left(y_{\text {oil }}-x_{\text {oil }}\right) \psi_{\text {conv }} C T O \\
& \frac{d y_{\text {gas }}}{d t}=\left(k_{3}\left(y_{\text {oil }}-x_{\text {oil }}\right)+k_{4} y_{\text {diesel }}\right) \psi_{\text {conv }} C T O \\
& \frac{d y_{\text {coke }}}{d t}=\left(k_{5}\left(y_{\text {oil }}-x_{\text {oil }}\right)+k_{6} y_{\text {diesel }}\right) \psi_{\text {coke }} C T O
\end{aligned}
$$

where $k_{1}, k_{2}, k_{3}, k_{4}, k_{5}, k_{6}$ are the reaction rate constants $\left(s^{-1}\right) ; y_{i}$ is the $i$-pseudocomponent mass fraction $\left(g_{i} / g_{\text {feed }}\right), x_{\text {oil }}$ is the uncrackable gas-oil mass fraction $\left(g_{\text {gasoil }} / g_{\text {feed }}\right)$ and CTO is the catalyst-oil ratio.

The activity function of coke formation $\psi_{\text {coke }}$ is described by the following equation:

$$
\frac{d \psi_{\text {coke }}}{d t}=-\alpha \psi_{\text {coke }}
$$

The activity function of conversion $\psi_{\text {conv }}$ is assumed the same for all the reactions:

$$
\frac{d \psi_{c o n v}}{d c_{c}}=-k_{d} \psi_{c o n v}
$$


where $\alpha$ is the deactivation constant for coke formation $\left(s^{-1}\right), k_{d}$ is the deactivation constant for conversion $\left(w t^{-1}\right)$ and $c_{c}$ is the coke content on the catalyst $(w t \%)$.

For the regenerator model, the catalyst phase is assumed to be perfectly mixed. Coke deposited on the catalyst in the reactor consists of carbon and hydrogen. It is assumed that all of the hydrogen in the coke is burned off in the regenerator. The complete hydrogen conversion takes place according to the reaction:

$$
4 \mathrm{H}+\mathrm{O}_{2} \rightarrow 2 \mathrm{H}_{2} \mathrm{O}
$$

Carbon in the coke reacts with oxygen to produce $\mathrm{CO}$ and $\mathrm{CO}_{2}$ by the following reactions:

$$
\begin{gathered}
2 \mathrm{C}+\mathrm{O}_{2} \rightarrow 2 \mathrm{CO} \\
\mathrm{C}+\mathrm{O}_{2} \rightarrow \mathrm{CO}_{2}
\end{gathered}
$$

Carbon monoxide reacts to produce carbon dioxide according to:

$$
2 \mathrm{CO}+\mathrm{O}_{2} \rightarrow 2 \mathrm{CO}_{2}
$$

The residual carbon remaining on the catalyst after regeneration is returned to the reactor with the regenerated catalyst, where additional coke is deposited. Both, reactor and regenerator mass and heat transfer are complex. Two zones frequently describe the regenerator model: a dense bed (with dense phase and gaseous phase) and an entrained catalyst zone. The dense bed is assumed to consist of two phases: a bubble phase of gaseous reactants and products moving up the bed in plug flow, and a perfectly mixed dense phase containing gas and solid catalyst. Mass transfer occurs between the two phases as gas moves up into the bed. Since the dense phase of the fluidised bed is assumed to be perfectly mixed, the temperature is uniform in the bed. The gaseous phase of the bed is assumed to be in equilibrium with the dense phase. Catalyst is presented in the space above the dense bed (the disengaging zone) due to the entrainment. The amount of catalyst decreases with upward vertical distance. As long as catalyst is presented, heat is generated by reactions (9) and (10), which affect the regenerator energy balance. In the region above the disengaging zone, the dilute phase, only reaction (11) is significant since so little catalyst is present. The regenerator model consists of the mass balance 
equations for $\mathrm{O}_{2}, \mathrm{CO}, \mathrm{CO}_{2}$ and coke, and the heat balance equations for the solid and the gaseous phases. These balance equations are correlated with equations describing entrained catalyst (bed characteristics) in the zone above dense bed, catalyst flow and pressure in the regenerator. Total combustion operation mode is considered.

The air blower model is a single stage centrifugal compressor driven by a variable speed steam turbine system. A head-capacity performance equation is provided that relates suction volume as a function of discharge pressure, where the suction is at normal atmospheric pressure. The wet gas compressor is modelled as a single stage centrifugal compressor driven by a constant speed electric motor. It is assumed that the compressor is pumping against a constant pressure in the vapour recovery unit. Circulation of spent and regenerated catalyst is modelled as single phase flow governed by force balance equations both on the spent and regenerated catalyst lines. Factors that affect catalyst circulation in a real FCCU, such as concentration of carbon on regenerated catalyst and injection of stream at various points in circulation bends have been ignored in this model. Constant friction factors are assumed for each circulation lines.

The distillation unit involves one of the most complex operations in the field of separation processes. The distillation products are mixtures of various hydrocarbon compounds and therefore, it is not possible to characterise them in terms of the individual components. A generally accepted practice is to express composition of crude oil and of the products in terms of a finite number of pseudocomponents. Each pseudocomponent, treated as a single component, is in fact a complex mixture of hydrocarbons and is characterised by an average boiling point and an average density (Halvorsen and Skogestad, 2003). The developed model consists in a continuous distillation column with 38 stages including a reboiler and a total condenser. The feed flow enters into the column at stage no. 8 and is considered, together with the feed composition, as the main source of disturbance,. The 114 order main fractionator model was developed under the following assumptions: a set of 3 peseudocomponents (as multicomponent mixtures) have been considered: gasoline, diesel and slurry (the heavy component); relative volatilities of the components are constant; vapour holdup is negleted; constant molar flows (same vapour flow on all stages) is assumed; total condensation is taking place in the condenser and no energy balance and hydrodynamics are explicitly considered. The first 38 states 
are compositions of gasoline, the next 38 states are compositions of diesel, the last 38 states are liquid holdups on each tray. The pressure balance in the main fractionator is also modelled, considering the main fractionator as a buffer vessel between reactor and wet gas compressor.

The new developed global model of the FCCU reactor-regenerator-main fractionator is a high order differential-algebraic equations system (DAE), consisting in 933 differential equations (ODEs) (133 equations from the mass, energy and momentum balance from the reactor stripper, regenerator, main fractionator, wet gas compressor, combustion air blower, catalyst circulation lines and 800 equations emerged from the discretization of the riser model, and together with more than 100 algebraic equations). The model was implemented in $\mathrm{C}$ programming language in order to obtaining an efficient solution and it was compiled for the Matlab/Simulink programming language to take advantage of its friendly graphical user interface. The model captures the major dynamic effects that may occur in an actual FCCU system. It is multivariable, strong interacting and highly nonlinear. First, the model it was used to study the dynamics of the process and then as internal part of the NMPC controller.

\subsection{FCCU modelling results}

The new developed dynamic simulator provides useful information regarding the open-loop dynamic behaviour of the global reactor-regenerator-fractionator system, predicting the composition of the main products (gasoline and diesel) during the disturbance action. Effects of different sets of disturbances have been studied. From this set, the progress of the most representative process variables in the presence of disturbance in the effective coke factor in the gas-oil feed $\left(K_{c}\right)$ is presented in Figure 3.

Figure 3. Simulation of FCCU dynamic behaviour in the presence of coking rate disturbance (5\% step increase at $t=200 \mathrm{~min})$

The effective coke factor $\left(K_{c}>0\right)$ is incorporated in the coke and wet gas yield model as a parameter that reflects the changes in the quality of the gas oil $\left(K_{c}=1\right.$ for normal gas oil, $K_{c}>1$ for 
heavier than normal gas oil, which yields to more coke formation, and $K_{c}<1$ for lighter than normal gas oil, with less coke production than in the base case). This type of disturbance simulates changes in properties of the feed oil resulting in the increase of the amount of coke deposited on the catalyst. For the industrial unit, this kind of coking rate change is possible to appear due to the fresh feed composition change or to disturbances in the recycle flow rate. The $5 \%$ increase in the coking rate determines the temperature rise in regenerator $T_{\text {reg }}$ by $2.5{ }^{\circ} \mathrm{C}$. The increase in the regenerator temperature induces an increase in the reactor temperature $T_{r}$ by $1^{0} C$, which leads to an intensification of cracking reactions with the effect on reactor pressure, $P_{4}$. The flowrate of spent catalyst $F_{s p}$ decreases, but it is superior to the regenerated catalyst flowrate $F_{r g c}$. The decrease of the regenerated catalyst flow decreases the catalyst-to-oil ratio, and this leads to a fast decrease of the coke amount in riser, coke $e_{\text {riser }}$. The decrease of the spent and regenerated catalyst flowrate has a direct consequence on the reactor and regenerator: the decrease of $10 \%$ (4 tons) in the catalyst inventory $W_{r}$ and the decrease of $0.07 \%$ ( 0.1 tons) in the regenerator catalyst inventory $W_{\text {reg. }}$ The coke amount in riser decrease; the net coke contribution decreases and for this reason, the combustion in the regenerator is performed in a diminished excess of oxygen ( $30 \%$ decreases of $\mathrm{O}_{2}$ concentration, $\left.X_{O 2}\right)$. The equilibrium of carbon is shifted to an increased amount of $\mathrm{CO}_{2}$ formation $\left(10.5 \%\right.$ increase of $\mathrm{CO}_{2}$ concentration, $\left.X_{\mathrm{CO} 2}\right)$. Taking into account the fact that heat generated by $\mathrm{CO}$ formation is about three times less than $\mathrm{CO}_{2}$ heat formation, the global effect is the reduction of the net heat contribution in the regenerator, with consequence on the relative small temperature decrease shown during the last part of the simulation. The $\mathrm{O}_{2}$ concentration increases and the $\mathrm{CO}_{2}$ amount decreases in the last period of the simulation due to the small decrease of the reactor pressure. This disturbance influences also the catalyst-to-oil ratio and the products composition in main fractionator. After a small peak, gasoline composition on the top of the column decreases and diesel composition increases. The selected disturbance has an important economical impact on the plant profit and gasoline octane number, due to the value of the main products obtained in the fractionator. A small increase or decrease of the products composition (gasoline and diesel) may have a significant profit effects taking into account the large production capacity of the plant. 


\subsection{Economical aspects}

With this simulator it was possible not only to study the process behaviour but it is also possible to investigate the plant gross profit and gasoline octane number, in order to take consistent decisions concerning the increase of the plant profitability.

Gross Profit of the FCCU may be formulated as:

$$
\begin{aligned}
\text { Profit }= & \text { column flow } \times \text { gasoline composition } \times \text { gasoline cost }+ \\
& + \text { column flow } \times \text { diesel composition } \times \text { diesel cost }- \text { raw material } \times \text { gasoil flow cost }
\end{aligned}
$$

The motor octane number $(M O N)$ and the research octane number $(R O N)$ have the following expressions (Ellis et al, 1998):

$$
\begin{aligned}
& M O N=72.5+0.05\left(T_{r}-900\right)+0.17(\xi-0.55) \\
& R O N=1.29 M O N+12.06
\end{aligned}
$$

where $T_{r}$ denotes the reactor temperature and $\xi$ is the conversion.

The gasoline octane number $(\mathrm{CO})$ may be computed by the following formula:

$$
C O=\frac{M O N+R O N}{2}
$$

The Plant Gross Profit and Gasoline Octane Number are sensitive to the coking rate disturbance $K_{c}$ allows:

- $\quad 5 \%$ increase in the coking rate results in the decrease the plant profit by $6.5 \%$,

- $\quad 5 \%$ increase in the coking rate leads to the increase of the $C O$ from 93.44 to 93.57 .

The FCCU model was validated using industrial process data from the ROMPETROL Refinery, Romania. Results obtained with the dynamic simulator present a good fit with industrial operating data, as simulated process variables are situated in a range corresponding to industrial unit behaviour, shown in Table 1:

Table 1. Typical operating conditions and values obtained with the simulator

\section{Nonlinear Model Predictive Control of the FCCU}


This section presents the novel Nonlinear Model Predictive Control algorithms applied for the control for the Fluid Catalytic Cracking of gas-oil.

In the wide variety of chemical processes, nonlinearity is rather the rule than the exception. Although it is well recognized that the performance of a control system is most dependent on how successfully it can cope with the nonlinearity of the process, chemical processes have been traditionally controlled by algorithms based on linear time-invariant approximate process models, the most common being step and impulse response models derived from the convolution integral. In the past decade, Model Predictive Control (MPC) has become a preferred control strategy for a large number of processes. The main reasons for this success consist in its ability to handle constraints in an optimal way and the flexibility of its formulation in the time domain. Linear MPC schemes, i.e. MPC schemes for which the prediction is based on a linear description of the plant, are by now routinely used in a number of industrial sectors and the underlying control theoretic problems, like stability, are well studied. Nonlinear model predictive control (NMPC), i.e. MPC based on a nonlinear plant description, has only emerged in the past decade and the number of reported industrial applications is continuously growing (Agachi et al, 2006).

\subsection{Nonlinear Model Predictive Control algorithm}

Nonlinear Model Predictive Control (NMPC) is an optimisation-based multivariable constrained control technique that uses a nonlinear dynamic process model for the prediction of the process outputs. At each sampling time, the model is updated based on new measurements and state variable estimates. Then, the open-loop optimal manipulated variable moves are calculated over a finite control horizon with respect to some cost function, and the manipulated variables for the subsequent control horizon are implemented (Chunyang et al, 2003, Allgöwer et al, 2004). Subsequently, the prediction horizon is shifted by usually one sampling time into the future and the previous steps are repeated, Figure 4. 
In the Figure 4, $r$ denotes the reference trajectory, which may be a filtered value of the demanded value $w, y$ is the controlled variable, $u$ is the manipulated variable, $N_{p}, N_{c}$ are the prediction and control horizon, $\Delta t$ is the sampling time.

A general formulation of the performance function may be developed and the optimisation problem to be solved at each sampling time can be formulated as follows:

$$
\min _{u(k) \ldots u\left(k+N_{c}-1\right)}\left\{\sum_{i=1}^{N_{p}}\left\|Q_{i}\left(r(k+i)-y_{P}(k+i)\right)\right\|^{2}+\sum_{i=1}^{N_{c}}\left\|R_{i} \Delta u(k+i-1)\right\|^{2}+\sum_{i=1}^{N_{c}}\left\|R_{i}^{\prime}\left(u(k+i-1)-u^{r e f}(k+i-1)\right)\right\|^{2}\right\}
$$

The predicted values of the output variables $y_{p}$ can be considered equal to the values obtained from the model $y_{m}$, but usually a correction is made to reduce the cumulative error effect of the measurement errors and the model/plant mismatch. The correction equation usually has the following form:

$$
y_{p}(k+i)=y_{m}(k+i)+K(k+i) \cdot\left(y_{m}(k)-y_{P}(k)\right)
$$

The decision variables in the optimisation problem are the control actions at $N_{c}$ sampling time steps into the future (control horizon). Generally, $1 \leq N_{c} \leq N_{p}$ and it is assumed that manipulated variables are constant beyond the control horizon. Although the optimisation provides a profile of the manipulated input moves over the entire control horizon, only the first control action is implemented. After the first control action implementation, new measurements are obtained which are used for the compensation of plant/model mismatch and for the estimation of unmeasured state variables. Finally, the prediction horizon $N_{p}$ is shifted by one sampling time into the future and the optimisation is performed again.

\subsection{NMPC with guaranteed stability}

Different NMPC approaches have been proposed that guarantee stability of the closed-loop system even under finite prediction horizon. The approach used in this paper is the so-called quasiinfinite horizon nonlinear MPC ( $I H N M P C)$ in which the prediction horizon is quasi-extended to infinity by introducing a terminal penalty term in the objective function. The basic idea of this approach consists in the approximation of the infinite prediction horizon to achieve closed-loop 
stability, whereas the input function to be determined on-line is of finite horizon. The terminal penalty term is added and determined off-line such as it bounds from above the infinite horizon objective function of the nonlinear function controlled by a local state feedback law. The terminal penalty term can be chosen to be quadratic when using a local linear feedback law and a quadratic objective function (Allgöwer et al., 1999, Nagy, 2001).

The key problem in this approach is the choice of the form and the off-line computation of the terminal region and penalty term, which is in general a difficult task because of the nonlinearity of the system (Chen and Allgöwer, 1998).

\subsection{NMPC with Moving Horizon Estimator}

In a typical industrial application, there is an important need to reconstruct unmeasured states based on a limited number of available measurements. A Moving Horizon Estimator (MHE) is employed for the states estimation. Benefits emerge because MHE incorporates physical state constraints into an optimisation formulation, accurately uses the nonlinear model and optimises over a trajectory of states and measurements (Haseltine and Rawlings, 2003). Considering as a nonlinear programming (NLP) problem, the MHE estimator approach may be formulated as follows:

Problem $P_{1}$ :

$$
\min _{x_{k-N, \theta_{e}}}\left\{J_{M H E}=\sum_{j=k-N+1}^{k}\left\|y_{i}-y_{i}^{\text {meas }}\right\|_{W}^{2}+\left\|\theta_{e}-\theta_{e}^{r e f}\right\|_{Z}^{2}\right\}
$$

subject to:

$$
\begin{aligned}
& x_{i}=f\left(x_{j-1}, u_{j-1}, \theta\right), j=k-N+1, \ldots, k \\
& y_{i}=g\left(x_{j}, \theta\right), j=k-N+1, \ldots, k \\
& \theta_{e, \min } \leq \theta \leq \theta_{e, \max }
\end{aligned}
$$

where $N$ is the estimation horizon, $W, Z$ are weighting matrices and $\theta_{e}$ is a subset of model parameters

selected for on-line adjustment. $\theta_{e}^{\text {ref }}$ is a set of reference values and $\theta_{e, \min }, \theta_{e, \max }$ are the specified 
lower and upper bounds for the adjustment parameters; $y_{i}$ denotes the output at discrete time $i$, and $y_{i}^{\text {meas }}$ is its corresponding measurement.

The second term of the problem $P_{l}$ penalizes parameter moves away from reference values, while the constraints ensure that parameter estimates stay within reasonable physical ranges. In the problem $P_{1}$ the inputs $u_{j}, j=k-N, \ldots, k-1$ are known inputs applied to the system. The solution of the problem $P_{1}$ is used to calculate an estimate of the controlled variable when the latter is not measured.

\subsection{Efficient solution of the NMPC optimisation via multiple shooting}

NMPC is typically implemented as a two-step algorithm consisting in the state estimation and the prediction, in order to minimize a specified control objective function. An NMPC algorithm must also be formulated to provide integral action in the feedback path. As the starting point for the development of the state estimation and predictive control algorithms the following general differential-algebraic optimisation problem is consider (Allgöwer et al, 2004):

Problem $P_{2}$ :

$$
\text { Minimize }\left\{J=\phi\left(x\left(t_{f}\right), t_{f}\right)+\int_{t_{0}}^{t_{f}} L[x(t), u(t), t] d t\right\}
$$

subject to:

$$
\begin{aligned}
& x(t)=f(x(t), u(t)) \\
& g(x(t), u(t))=0 \\
& h(x(t), u(t)) \leq 0
\end{aligned}
$$

where $J$ is the state estimation or predictive control objective function, $x(t)$ and $u(t)$ are the state and input vectors, respectively, and $f$ and $g$ represent the mechanistic model of the system consisting in a set of coupled differential and algebraic equations and $h$ represents the bounds on system variables or other linear or nonlinear constraints. 
Problem $P_{2}$ can neither be solved by typical NLP techniques nor by optimal control methods. In general, NLP methods cannot optimise continuous systems while optimal control methods do not handle algebraic constraints for $g$ and $h$. Considering the discrete nature of the online control problem, a convenient approach for solving problem $P_{2}$ is to formulate its discrete approximation that can be handled by conventional NLP solvers. For its generality, an alternating formulation for the discrete approximation of the Nonlinear Model Predictive Control problem is considered, Problem P3. The prediction horizon $\left[0, t_{f}\right]$ is divided into $p$ equally spaced time intervals $\Delta t$, with discrete time $k+i$ representing $t=i \Delta t, i=0,1 \ldots p$.

\section{Problem P3:}

$$
\min _{u_{k \mid,} u_{k+1 \mid k} \ldots, u_{k+m-I \mid k}}\left\{J_{N L M P C}=\sum_{j=k+1}^{k+p}\left\|y_{j \mid k}^{c}-d_{k}-y_{j}^{r e f}\right\|_{Q}^{2}+\sum_{j=k}^{k+m-1}\left(\left\|u_{j \mid k}-u_{j}^{r e f}\right\|_{R}^{2}+\left\|\Delta u_{j \mid k}\right\|_{S}^{2}\right)\right\}
$$

subject to:

$$
\begin{aligned}
& x_{j \mid k}=f\left(x_{j-1 \mid k,} u_{j-l \mid k}, \theta\right), j=k+1, \ldots, k+p \\
& y_{j \mid k}^{c}=g\left(x_{j \mid k}, \theta\right), j=k+1, \ldots, k+p \\
& y_{\text {min }}^{c} \leq y_{j / k}^{c} \leq y_{\text {max }}^{c}, j=k+1, \ldots, k+p \\
& u_{\text {min }} \leq u_{j \mid k} \leq u_{\text {max }}, j=k, \ldots, k+m-1 \\
& \Delta u_{\min } \leq \Delta u_{j \mid k} \leq \Delta u_{\max }, j=k, \ldots, k+m-1 \\
& u_{j \mid k}=u_{j-l \mid k}, j=k+m-1, \ldots, k+p-1
\end{aligned}
$$

where $p$ is the prediction horizon, $m$ is the control horizon, $u_{j \mid k}$ is the process input variable and $y_{j \mid k}^{c}$ is the controlled output variable at the discrete time $j$, calculated from information available up to the discrete time $k ; \Delta u_{j \mid k}=u_{j \mid k}-u_{j-1 \mid k}, j=k, \ldots k+m-1$, are present in the objective function to allow excessive input moves to be penalized and constrained if necessary; $d_{k}$ is an estimate of unmeasured disturbance at time $k$, and is required in the control formulation to ensure offset free operation of the controller. 
At each control interval, the entire Problem $P_{3}$ is solved but only the input $u_{k}=u_{k \mid k}$ is implemented. $Q, R, S$ are the weighting matrices and $\theta$ is a vector of model parameters. The target trajectories $y^{r e f}, u^{r e f}$ are obtained from the solution of an off-line dynamic optimisation problem.

A very efficient solution technique for the Problem $P_{3}$ is based on the multiple shooting approach (Diehl et al, 2002). This procedure consists in dividing the time interval $t \in\left[t_{0}, t_{f}\right]$ into a series of grid points $\left[t_{0}, t_{1}, t_{2}, \ldots, t_{f}\right]$. Using local control parameterisations, a shooting method is performed between successive grid points, Figure 5. The differential equations and cost on these intervals are integrated independently during each optimisation iteration, based on the current guess of the control. The continuity/consistency of the final state trajectory at the end of the optimisation is enforced by adding consistency constraints to the nonlinear programming problem. A set of starting values for the state and adjoint vectors is required at each grid point in time. Continuity conditions for the solution trajectory introduce additional interior boundary conditions, which are incorporated into one large zero-finding problem to be solved. The solution of Problem $P_{2}$ is performed using an NMPC tool, OptCon, (Nagy et al., 2004) based on the sequential-quadratic-programming (SQP) type optimiser HQP. The NMPC tool developed includes a number of desirable features. In particular, the NMPC is based on first-principle models, and the problem can be set up in Matlab (The Mathworks Inc.), which is the most widely used modeling and control environment for control engineers. The model used in the controller has to be developed in the form of Simulink (The Mathworks Inc.) "mex S-function" using C language. The S-function interface of the optimization tool provides convenient and fast connectivity with Matlab. The NMPC approach is based on a state-of-the-art large-scale nonlinear optimization solver, HQP, (Franke et al.) which offers one of the most efficient approaches, based on the multiple shooting algorithm, that exploits the special structure of optimization problem that arise in NMPC. HQP is used in conjunction with the implicit differential-algebraic-equation (DAE) solver, DASPK, for robust and fast solution finding of the model equations. OptCon provides a very efficient tool for rapid prototyping NMPC applications even in industrial environment (Nagy et al., 2007). 


\section{Figure 5. Illustration of the multiple shooting approach}

The solution of the Problem $P_{2}$ requires a certain, usually not negligible, amount of computation time, while the system is evolving to a different state. In this case, the optimal feedback control $u^{*}\left(t_{k}\right)=\left[u_{0 \mid t_{k}}, u_{1 \mid t_{k}}, \ldots, u_{p \mid t_{k}}\right]$ computed at the moment $t_{k}$ and corresponding to the information available up to this moment will no longer be optimal. Computational delay $\delta_{k}$ has to be taken into consideration in real-time applications. First, at time moment $t_{k}$, the control input from the second stage of the previous optimisation problem, $u_{\left.1\right|_{k-1}}$ (which corresponds to the first stage of the current optimization) is injected into the process. Then, the solution of the current optimisation problem is started, with fixed $u_{0 \mid t_{k}}=u_{\left.1\right|_{k-1}}$. After completion, the optimisation idles for the remaining period of time $t \in\left(t_{k}+d_{k}, t_{k+1}\right)$, and then at the beginning of the next step (at the moment $t_{k+1}=t_{k}+\Delta t$ ), $u_{1 \mid t_{k}}$ is introduced into the process and the algorithm is repeated. This approach requires real-time feasibility for the solution of each open-loop optimisation problems $\left(d_{k} \leq \Delta t\right)$.

\subsection{NMPC FCCU simulation results}

The complex dynamic model of the FCCU was used in the NMPC algorithm. First, the nominal NMPC was considered without the penalty term and terminal constraints, in order to test different control structures under different disturbance scenarios. From the performed simulations it is presented the $5 \times 5$ (controlled $\times$ manipulated variables) control structure. The five controlled variables are: reactor temperature $T_{r}$, fractionator pressure $P_{5}$, reactor catalyst inventory $W_{r}$ and gasoline composition at the top and bottom of the main fractionator. The five manipulated inputs are: slide valve positions $s v s c$ and $\operatorname{svrgc}$ on the spent and regenerated catalyst circulation lines, stack valve position $V_{14}$, condenser's liquid flowrate $L T$ and reboiler's liquid flowrate VB, Figure 6 . The coking rate $K_{c}$ change (step increase at moment $t=10 \mathrm{~min}$ ) has been selected as a typical disturbance.

The control of presented variables is important for the efficient and safe operation of the unit and have direct impact on the products yield. The reactor temperature has to be maintained at a certain 
level to provide a desired maximum conversion of the feed oil. A proper reactor temperature control means also a good management of thermal energy. Control of reactor catalyst inventory is necessary to provide stabilization and safety in the catalyst circulation. Reactor pressure control directly influences the coke and gases formation. Composition of the products must be maintained at desired certain values to assure the products quality and plant productivity.

Figure 6. Simulation of FCCU dynamic behaviour in the presence of the coking rate disturbance (1\% step increase $t=10 \mathrm{~min}$ ); NMPC results (dotted line) and open loop modelling results (solid line); (a) - controlled variables; (b)- manipulated variables

The QIHNMPC algorithm was applied for a control structure with the three controlled variables: reactor temperature $T_{r}$, regenerator temperature $T_{\text {reg }}$ and catalyst inventory in the reactor $W_{r}$. The corresponding three manipulated inputs were: spent and regenerated catalyst circulation slide valve position $s v s c$ and $\operatorname{svrgc}$, and the fresh feed flow entering the reactor riser $F_{3}$. Figure 7 illustrates the performance of the QIHNMPC for different off-nominal initial conditions of the reactor temperature, $T_{r}$ ), considered as different disturbance scenarios for the investigated control scheme. It may be noticed that asymptotic stability is achieved in all cases. The very small terminal region (projections of the hyper-ellipsoid on the shown state space) is caused by the strong nonlinearity of the system.

Figure 7. Trajectories for the system controlled by QIHNMPC

The QIHNMPC results have been compared with the nominal NMPC considered without the penalty term and the terminal constraints. Figure 8 shows that QIHNMPC achieves better control performance compared to the nominal NMPC, however with increased computational burden. By the use of QIHNMPC the system is stabilized faster (different figure scales are used to show details). 
Figure 8. Comparison between QIHNMPC and NMPC for $16^{\circ} \mathrm{C}$ disturbance in $T_{r}$; QIHNMPC results (solid line) and NMPC results (dotted line); (a)-controlled variables; (b)- manipulated variables

The efficient implementation of the continuous time output feedback Nonlinear Model Predictive Control using a Moving Horizon Observer (MHE) for the FCCU states estimation was also investigated. For the output feedback NMPC approach applied in this work and by the use of the MHE technique, only measurements that are available in practice are considered, whereas the rest of the states are estimated together with the uncertain model parameters.

Figure 9 comparatively presents the open-loop simulation results of the FCC plant and the simulation results using the MHE algorithm in the presence of the coke disturbance factor $K_{c .}(0.9 \%$ increase at $t=45 \mathrm{~s}$ ). The considered disturbance influences the reactor temperature $T_{r}$, the regenerator temperature $T_{\text {reg }}$, the regenerator $W_{\text {reg }}$ and reactor $W_{r}$ catalyst inventories, the carbon inventory in the regenerator (number moles in regenerator) $n$ but also has an important impact on the system pressure: combustion air blower suction pressure $P_{1}$, combustion air blower discharge pressure $P_{2}$, fractionator pressure $P_{5}$, regenerator pressure $P_{6}$ and wet gas compressor suction pressure $P_{7}$. Figure 9 presents the evolution of the FCCU model states using the following available measurements found in practice: $T_{r}$, $T_{\text {reg }}, P_{1}, P_{2}, P_{5}, P_{6}$. The MHE reconstructs the states of the FCCU system from process measurements but also estimates the unknown model parameter $K_{c}$. As may be noticed, a few states are difficult to be estimated (e.g. $W_{\text {reg, }} W_{r}$, and $n$ ). However the estimator achieves excellent performance in estimating the unknown model parameter $K_{c}$.

Figure 9. Performance of the MHE in the case of the $K_{c}$ disturbance $(0.9 \%$ step increase at $t=2 \mathrm{~min})$ - MHE results (dotted line) and open-loop modelling results (solid line)

The combined MHE-NMPC algorithm was applied for the FCCU reactor and regenerator temperature control, in the case of the column pressure $P_{5}$ disturbance $(3 \%$ step decrease at the 
beginning of simulation) using as manipulated variables the input flow rate in the reactor riser $F_{3}$ and the slide valve position on the spent catalyst pipe svsc, Figure 10. The overall performance of the MHE-NMPC is very good as the temperatures are kept close to the reference values.

Figure 10. Simulation results of the MHE-NMPC in the case of the $P_{5}$ disturbance $(3 \%$ step decrease at $t=0 \mathrm{~min})$

The CPU computational times corresponding to the MHE and NMPC calculations are presented in Figure 11. The dimension of the optimisation problem for the NMPC is only two, since a control horizon of only one sampling time is used, whereas the dimension of the optimisation problem of the MHE is high due to the large number of FCC model states, thus leading to a significantly higher computational effort. Figure 11 demonstrates the efficiency of the multiple shooting approach .The computational time scales only linearly with dimension of the optimisation problem and the maximum total computational time (approximately $13 \mathrm{~s}$ ) is well bellow the sampling time of $120 \mathrm{~s}$. The results demonstrate that efficient optimisation algorithms can guarantee the real-time feasibility of the MHENMPC implementation even for a model with a large number of ODEs (as 933 ODEs have been used in the presented investigation).

Figure 11. CPU times required for the optimisation problems of the MHE and NMPC

A comparative study of FCCU control has been also performed for different MPC algorithms (based on linear and nonlinear FCCU models) and the classical PID control. The results are presented in the Figure 12 and Figure 13. As controlled variables have been chosen the reactor temperature $T_{r}$, the regenerator temperature $T_{r e g}$ and catalyst inventory $W_{r}$. As manipulated variables, the spent and regenerated catalyst circulation lines slide valve positions $s v s c$, $\operatorname{svg} c$ and the fresh feed flow entering in riser $F_{3}$ have been used. The chosen disturbance is the pressure drop between main fractionator and reactor disturbance $\Delta P_{\text {frac }}(27 \%$ step decrease at $t=12 \mathrm{~min})$. 
Figure 12. Comparison between different FCCU control approaches in the presence of the pressure drop disturbance ( $27 \%$ step decrease at $t=12 \mathrm{~min}$ ), the controlled variables; a) LMPC (dotted line); NMPC (solid line) and b) PID control

Figure 13. Comparison between different FCCU control approaches in the presence of the pressure drop disturbance (27\% step decrease at $t=12 \mathrm{~min})$, the manipulated variables; a) LMPC (dotted line); NMPC (solid line) and b) PID control

MPC based on the nonlinear NMPC performs better FCCU control compared to the MPC based on the linear LMPC, and both show superior control performance then classical PID control.

\section{Conclusions}

The paper presents the new model and dynamic simulation results for the FCCU reactorregenerator-main fractionator aggregate system using a five lump kinetic model for the riser. The model consists in a set of 933 ODEs. Based on this complex nonlinear model, different Model Predictive Control based algorithms have been investigated for the FCCU control. A $5 \times 5$ control scheme is proposed and proved as being able to control the gasoline obtained from the main fractionator. The model was subsequently used to simulate the performance of the quasi-infinitehorizon NMPC in order to achieve fast stabilization of the closed-loop system. It is shown that using state-of-the-art optimization approaches based on the modern multiple shooting algorithm the realtime feasibility can be achieved even in the case of the very high order FCCU model. The paper also assesses the good performance of the Moving Horizon Estimation based Nonlinear Model Predictive Control approach for this case of the highly complex industrially relevant process represented by FCCU. The appropriate estimation of the model states or unmeasurable parameters is critical to the success of model based process monitoring and control applications. NMPC algorithms perform very well in tracking the setpoints and rejecting disturbances and simulations proved that the MPC based on the nonlinear model is successful, despite the complex nonlinear features of the FCC system. NMPC 
performs better then the LMPC and both are significantly better then the classical PID control, regarding settling time, overshoot and keeping controlled variables close to the operation or equipment constraints. The results demonstrate that industrial applications of modern NMPC approaches to complex chemical processes can be brought in the realm of possibility. Simulation results demonstrate that using state-of-the-art optimization algorithms and advanced control together with estimation strategies can be implemented on complex industrially relevant problems. The results of the proposed control structures encourage the application of the new control scheme to the industrial systems.

\section{Nomenclature}

$c_{c} \quad$ coke content on the catalyst (wt\%)

$\mathrm{CO}$ gasoline octane number

CTO catalyst-to-oil ratio

coke $e_{\text {riser }}$ coke amount in riser

$d_{k} \quad$ estimate of unmeasured disturbance at time $k$

$f \quad$ mechanistic model of the system consisting in a set of coupled differential and algebraic equations

$F_{r g c} \quad$ flowrate of regenerated catalyst $(\mathrm{kg} / \mathrm{s})$

$F_{s p} \quad$ flowrate of spent catalyst $(\mathrm{kg} / \mathrm{s})$

$F_{3} \quad$ flow of fresh feed to reactor riser $\left(\mathrm{m}^{3} / \mathrm{h}\right)$

$g$ mechanistic model of the system consisting in a set of coupled differential and algebraic equations

$h \quad$ bounds on system variables or other linear or nonlinear constraints

$K_{c} \quad$ effective coke factor for gas-oil feed

$k_{d} \quad$ deactivation constant for conversion $\left(w t^{0} \%^{-1}\right)$

$k_{i} \quad$ reaction rate constants $\left(s^{-1}\right)$

$J \quad$ state estimation or predictive control objective function

$L T \quad$ condenser's liquid flow $(\mathrm{kg} / \mathrm{min})$

$n \quad$ number moles in regenerator (moles)

$N \quad$ estimation horizon

$N_{c} \quad$ control horizon

$N_{p} \quad$ prediction horizon

$P_{1} \quad$ combustion air blower suction pressure (bar)

$P_{2} \quad$ combustion air blower discharge pressure (bar)

$P_{4} \quad$ reactor pressure (bar)

$P_{5} \quad$ fractionator pressure (bar)

$P_{6} \quad$ regenerator pressure (bar)

$P_{7} \quad$ wet gas compressor suction pressure (bar)

$Q \quad$ weighting matrice

$r \quad$ reference trajectory

$R \quad$ weighting matrice

svsc slide valve positions on the spent catalyst circulation line (0-1)

svrgc slide valve positions on the regenerated catalyst circulation line $(0-1)$

$S \quad$ weighting matrice

$T_{r} \quad$ temperature of reactor $\left({ }^{\circ} \mathrm{C}\right)$ 


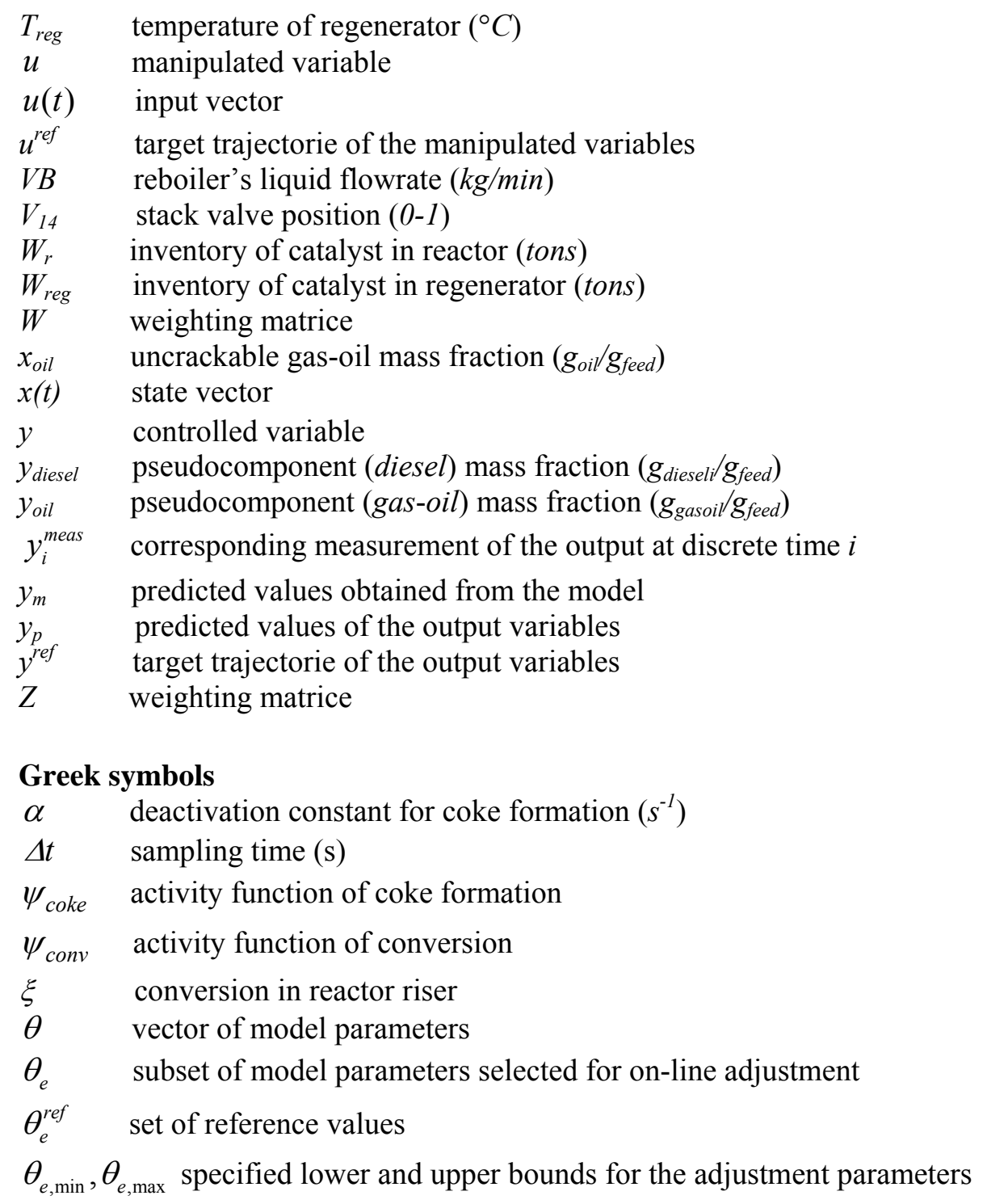

\section{Acknowledgements}

This work was supported by the Marie Curie fellowship HPMT-CT-2001-00278. The authors are also gratefully to the ROMPETROL Refinery for their support.

\section{References}

[1] McFarlane, R.C., Rieneman R.C., Bartee J.F., \& Georgakis C. (1993). Dynamic simulator for a model IV Fluid Catalytic Cracking Unit. Comp. Chem. Engng., 17, 275.

[2] Cristea, M. V., Agachi S.P., \& Marinoiu V. (2003). Simulation and Model Predictive Control of a UOP Fluid Catalytic Cracking Unit. Chem. Engng. Proc., 42, 67.

[3] Qin, S.J., \& Badgewell T, (2003). A survey of industrial Model Predictive Control technology, Contr. Engng. Prac, 11, 733. 
[4] Sadeghbeigi, R. (2000). Fluid Catalytic Cracking Handbook, USA: Buterworth-Heinemann.

[5] Dupain, X., Gamas E. D., Madon R., Kelkar C.P., Makkee M., \& Moulijin J.A. (2003). Aromatic gas-oil cracking under realistic FCC conditions in a microriser reactor. Fuel, 82, 1559.

[6] Halvorsen, I.J., \& Skogestad, S. (2003). Minimum Energy Consumption in Multicomponent Distillation. Part 1- Vmin Diagram for a Two-Product Column. Ind. Engng. Chem. Res. 42, 594.

[7] Ellis, R., Li, X., \& Riggs, J. (1998). Modelling and optimization of a model IV fluidized Catalytic Cracking Unit. AIChE J., 9, 44, 2068.

[8] Agachi, P. S., Nagy, Z. K., Cristea, M. V., \& Imre-Lucaci, A.I. (2006). Model Based Control. Wiley-VCH Verlag GmbH \& Co. KgaA.

[9] Chunyang, J., Rohani S., \& Jutan A. (2003). FCC unit modelling, identification and Model Predictive Control- a simulation study. Chem. Engng. Proc, 42, 311.

[10] Allgöwer, F., Findeisen R., \& Nagy Z.K. (2004). Nonlinear Model Predictive Control: from theory to application. J. Chin. Inst. Chem. Engrs., 35, 299.

[11] Allgöwer, F., T.A. Badgwell, J.S. Quin, J.B. Rawlings, \& Wright, S.J. (1999). Nonlinear Predictive Control and Moving Horizon Estimation-An introductory overview. Adv. Contr, 391.

[12] Nagy, Z. K. (2001). Model Predictive Control techniques for chemical processes. PhD Thesis, Babes-Bolyai University.

[13] Chen H., \& Allgöwer F. (1998). A Quasy-Infinite Horizon Nonlinear model Predictive Control Scheme with Guaranteed Stability. Automatica, 34, 1205.

[14] Haseltine, L.E., \& Rawlings J.B. (2005). Critical evaluation of extended Kalman filtering and moving horizon estimation. Ind. Eng. Chem. Res., 44, 2451.

[15] Diehl, M., Bock, H.G., Schloeder, J.PG., Findeisen, R., Nagy, Z.K., \& Allgöwer, F. (2002). Realtime optimization and Nonlinear Model Predictive Control of processes governed by differentialalgebraic equations. J. Proc. Contr, 12, 577.

[16] Nagy, Z.K., Allgöwer F., Franke R., Frick A., \& Mahn B. (2004). Efficient tool for nonlinear model predictive control of batch processes. Proc. of the $12^{\text {th }}$ Mediterranean Conference on Control and Automation (MED'04), Kusadasi, Turkey, on CD. 
[17] Franke, R., E. Arnold, and H. Linke. HQP: A solver for nonlinearly constrained large-scale optimization. http://hqp.sourceforge.net.

[18] Nagy, Z. K., B. Mahn, R. Franke, F. Allgower (2007). Efficient output feedback nonlinear model predictive control for temperature control of industrial batch reactors, Control Engineering Practice,, 15, 839-859, 2007.

[19] Baldea, M., P. Daoutidis and A. Kumar (2006). Dynamics and Control of Integrated Process Networks with Purge Streams, AIChE J., 52, 1460-1472.

[20] Engell, S. (2007). Feedback Control for Optimal Process Operation. Journal of Process Control $17,203-219$.

[21] Skogestad, S. (2004). Control structure design for complete chemical plants. Computers \& Chemical Engineering, 28 (1-2), 219-234.

[22] Araújo, A.C.B., Govatsmark, M. Skogestad, S. (2007). Application of plantwide control to the HDA process. I - steady-state optimization and self-optimizing control. Control Engineering Practice, $15(10), 1222-1237$.

[23] Nagy, Z.K., R.D. Braatz (2003). Robust nonlinear model predictive control of batch processes, AIChE J. 49, 1776-1786. 



\section{Figures}

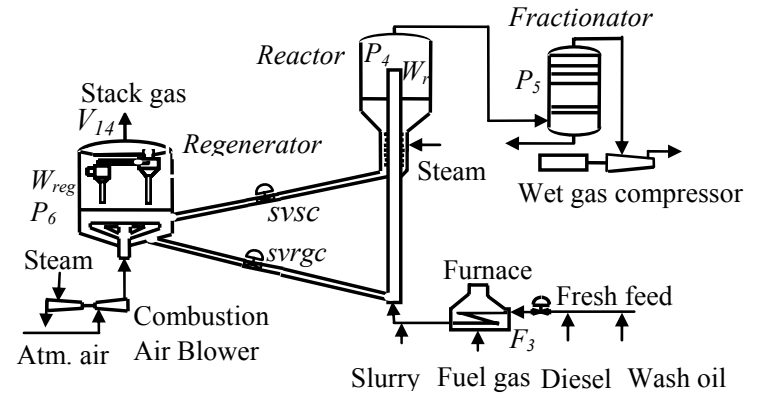

Figure 1. FCCU plant

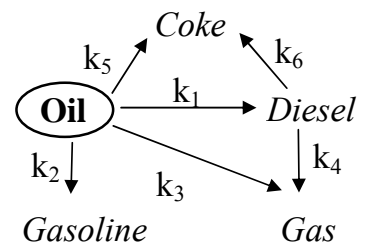

Figure 2. Five lump model for the catalytic cracking 

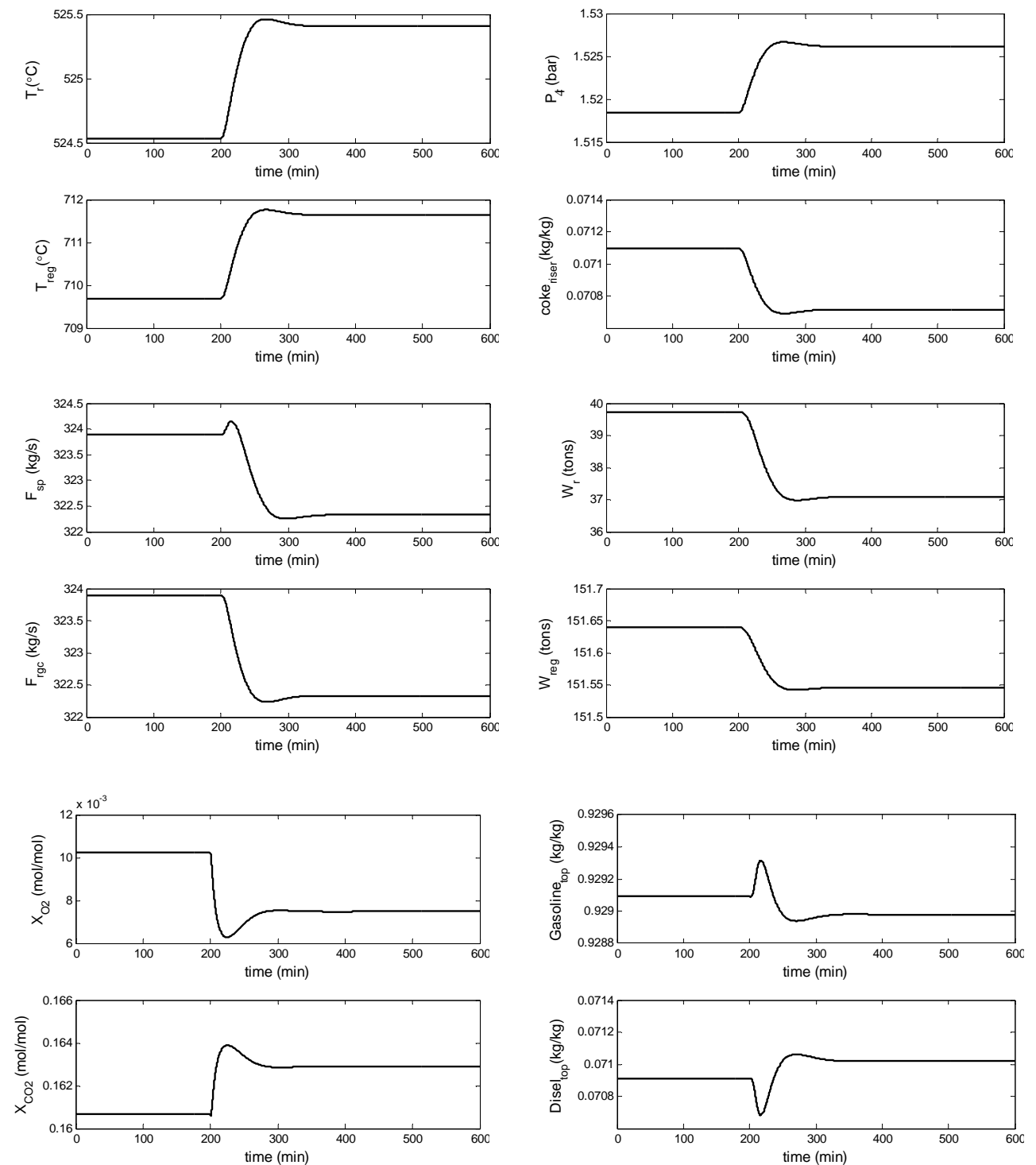

Figure 3. Simulation of FCCU dynamic behaviour in the presence of coking rate disturbance (5\% step increase at $t=200 \mathrm{~min}$ ) 


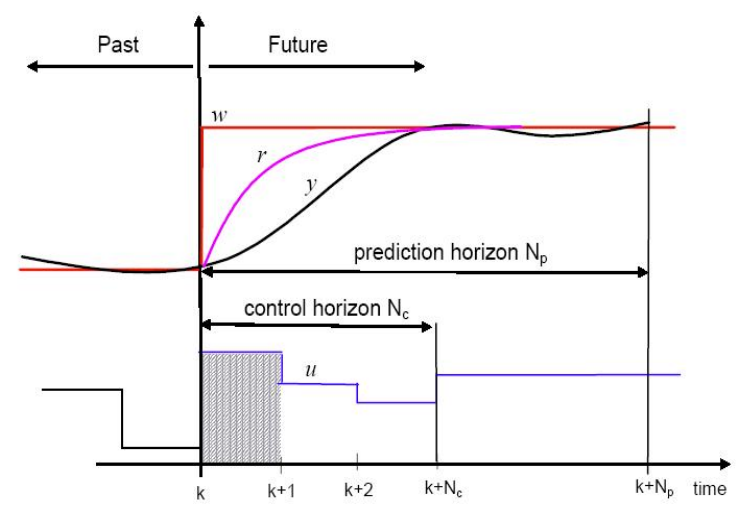

Figure 4. NMPC algorithm

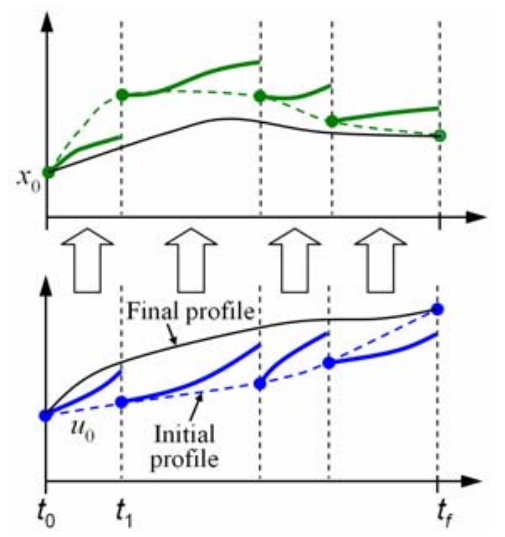

Figure 5. Illustration of the multiple shooting approach 

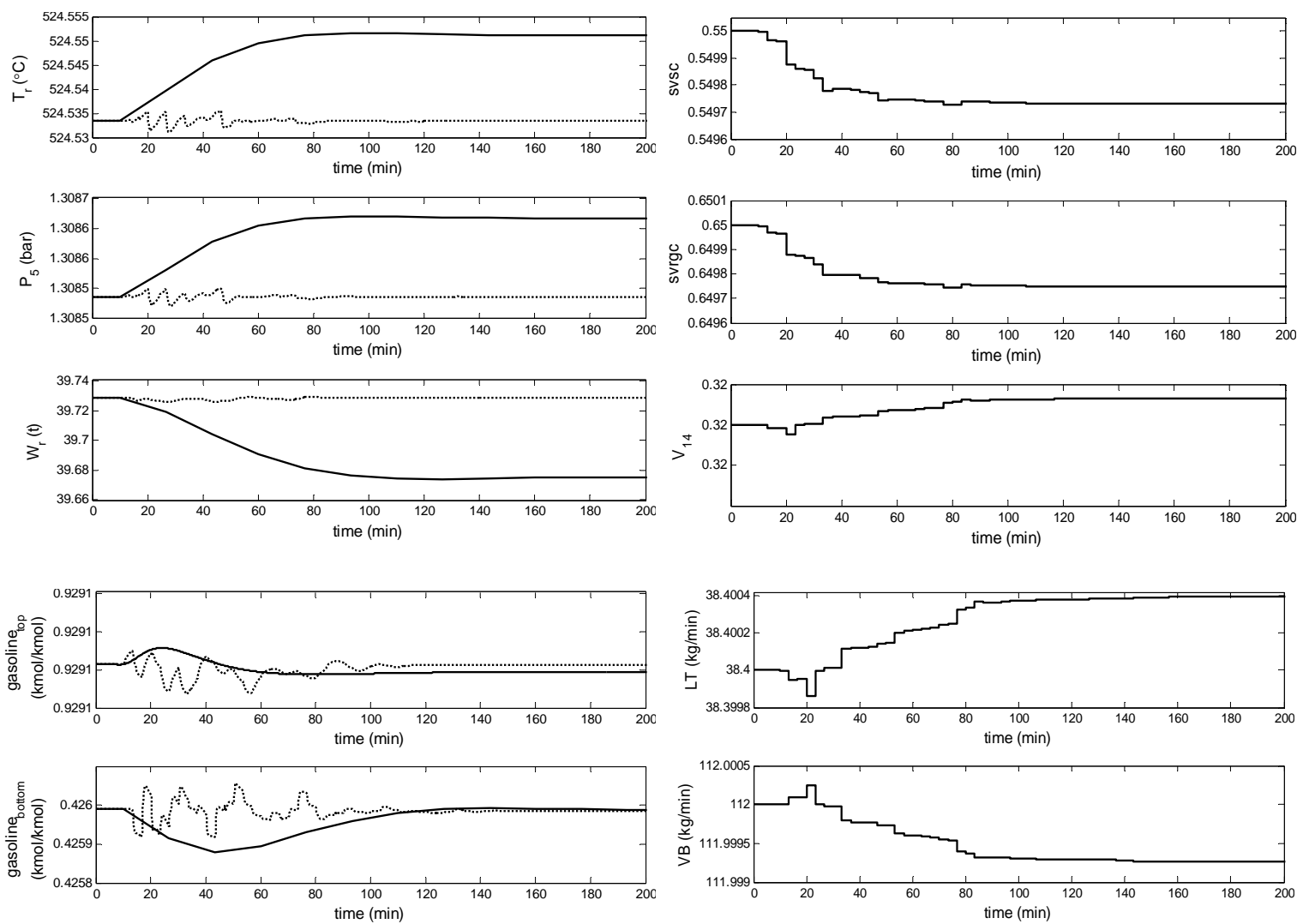

a)

b)

Figure 6. Simulation of FCCU dynamic behaviour in the presence of the coking rate disturbance (1\% step increase $t=10 \mathrm{~min}$ ); NMPC results (dotted line) and open loop modelling results (solid line); a) controlled variables ; b)- manipulated variables 

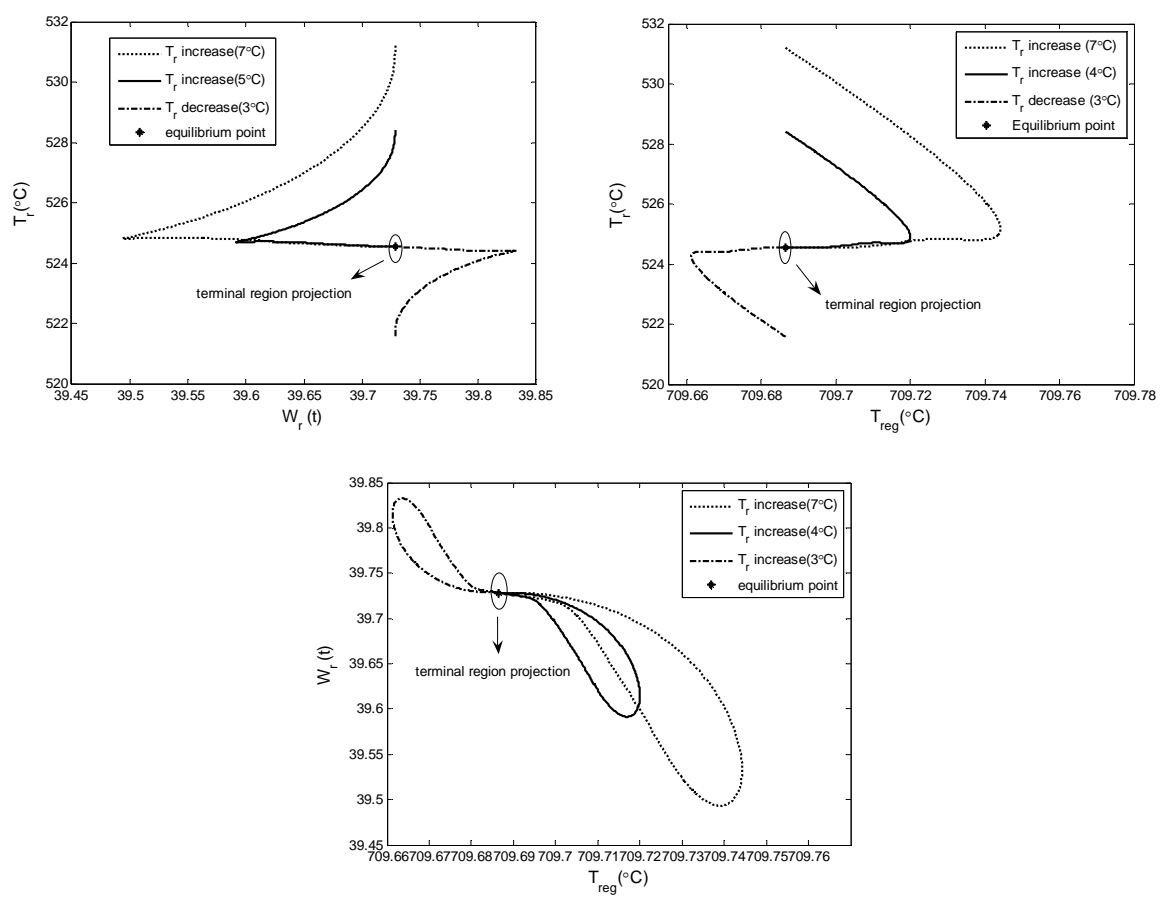

Figure 7. Trajectories for the system controlled by QIHNMPC
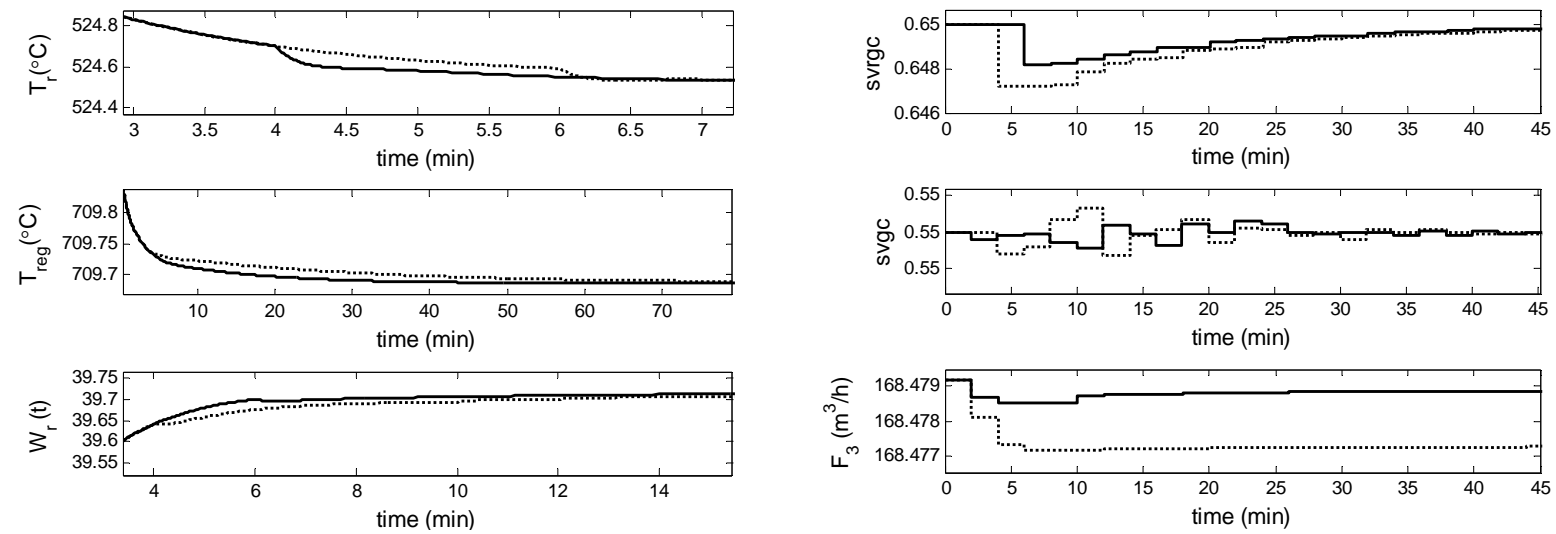

a)

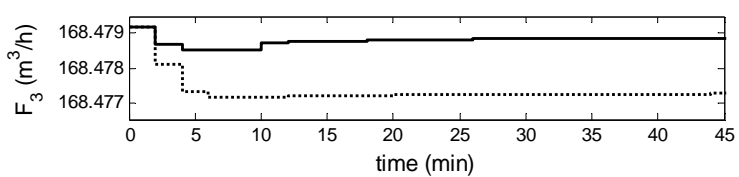

b)

Figure 8. Comparison between QIHNMPC and NMPC for $16^{\circ} \mathrm{C}$ disturbance in $T_{r}$; QIHNMPC results (solid line) and NMPC results (dotted line); (a)-controlled variables; (b)-manipulated variables 

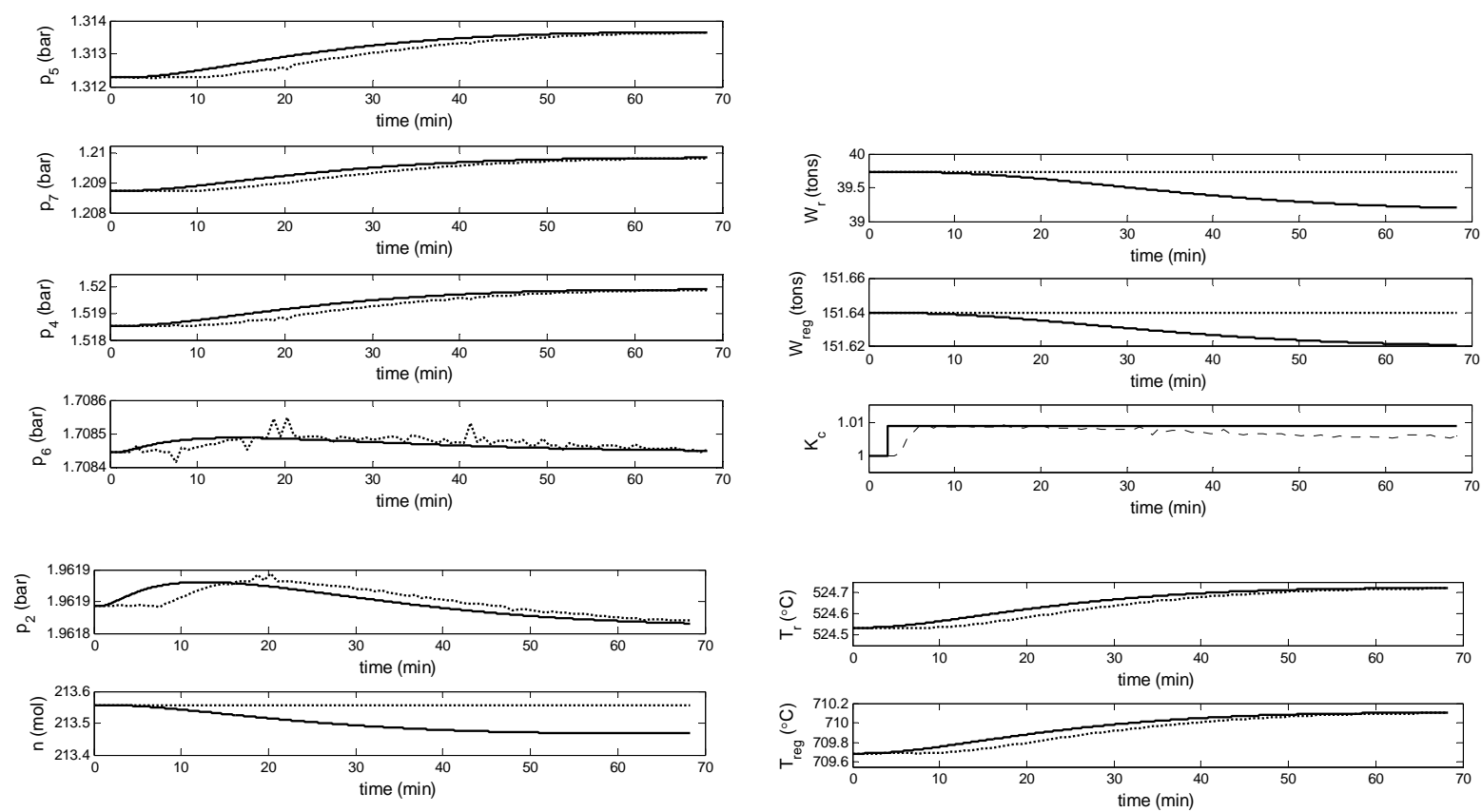

Figure 9. Performance of the MHE in the case of the $K_{c}$ disturbance ( $0.9 \%$ step increase at $\left.t=2 \mathrm{~min}\right)$

- MHE results (dotted line) and open-loop modelling results (solid line)
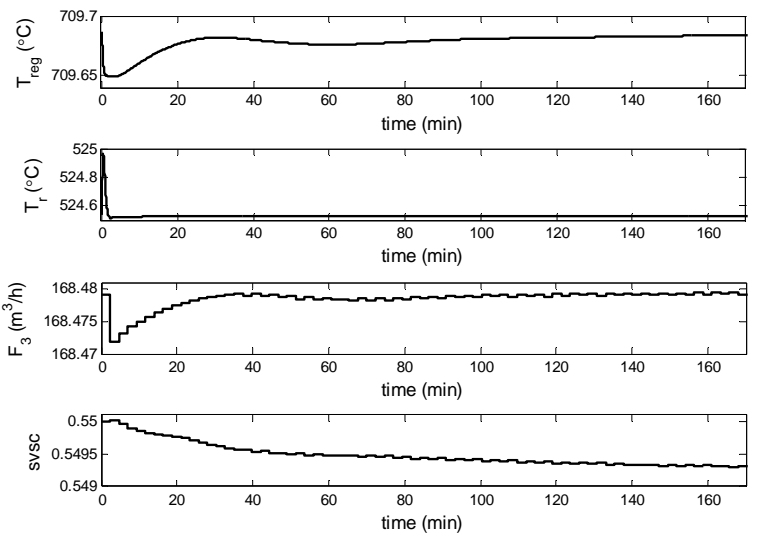

Figure 10. Simulation results of the MHE-NMPC in the case of the $P_{5}$ disturbance (3\% step decrease at $t=0 \mathrm{~min})$ 

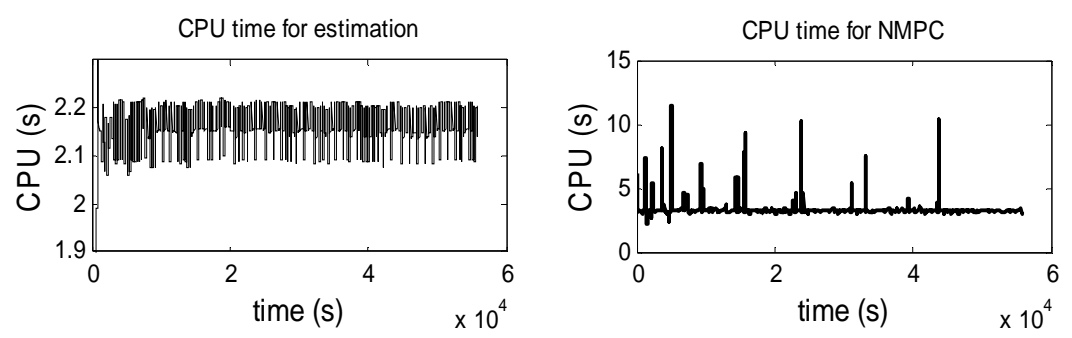

Figure 11. CPU times required for the optimisation problems of the MHE and NMPC
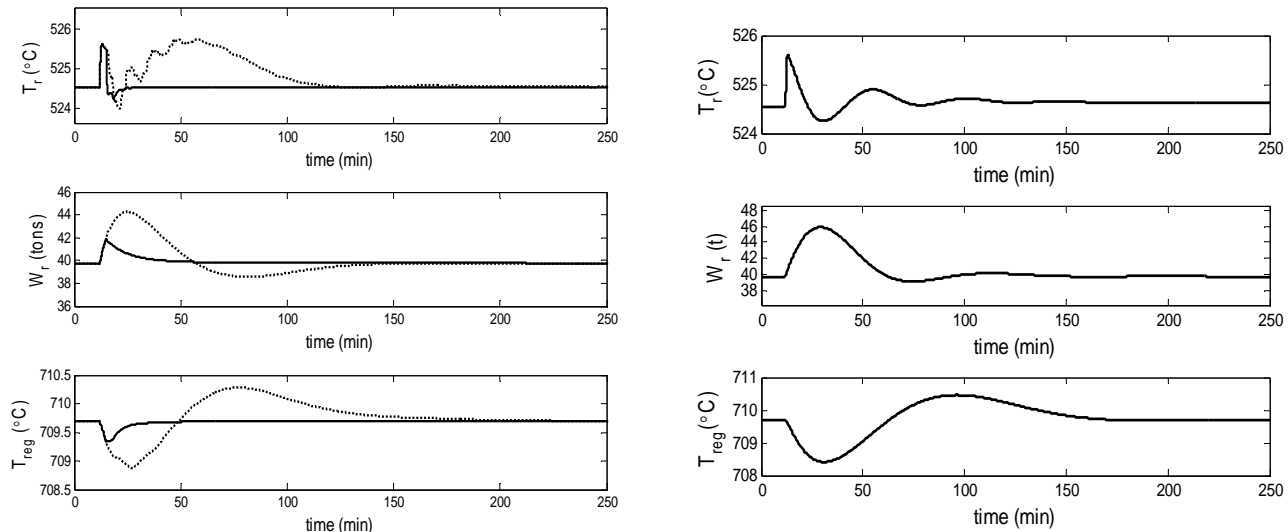

a)

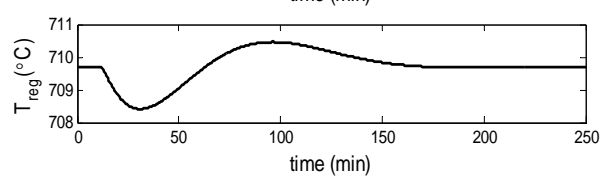

b)

Figure 12. Comparison between different FCCU control approaches in the presence of the pressure drop disturbance (27\% step decrease at $t=12 \mathrm{~min})$, the controlled variables; a) LMPC (dotted line); NMPC (solid line) and b) PID control 

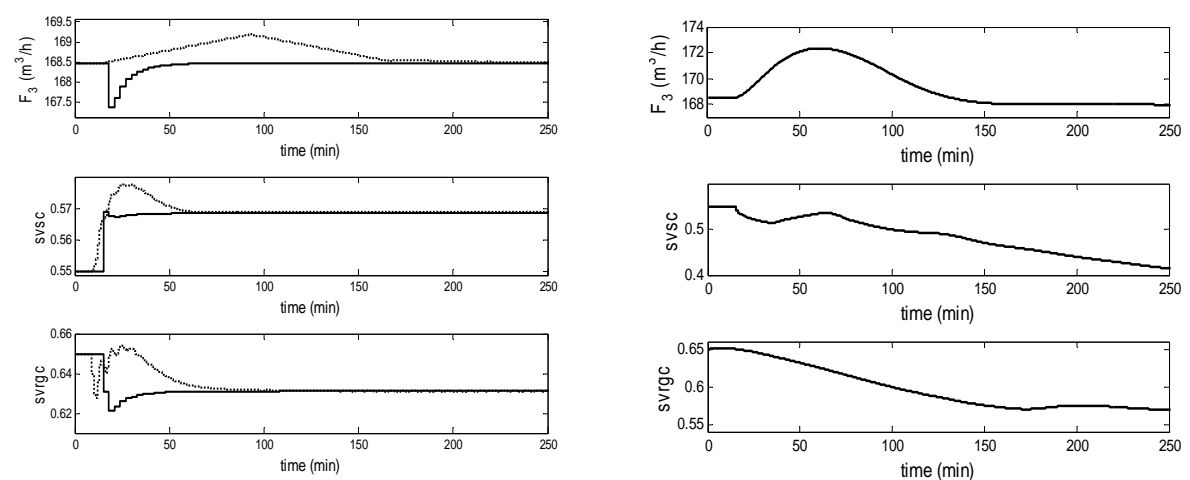

a)

b)

Figure 13. Comparison between different FCCU control approaches in the presence of the pressure drop disturbance (27\% step decrease at $t=12 \mathrm{~min}$ ), the manipulated variables; (a) LMPC (dotted line); NMPC (solid line) and (b) PID control 


\section{Figure Caption}

Figure 1. FCCU plant

Figure 2. Five lump model for the catalytic cracking

Figure 3. Simulation of FCCU dynamic behaviour in the presence of coking rate disturbance (5\% step increase at $t=200 \mathrm{~min}$ )

Figure 4. NMPC algorithm

Figure 5. Illustration of the multiple shooting approach

Figure 6. Simulation of FCCU dynamic behaviour in the presence of the coking rate disturbance (1\% step increase $t=10 \mathrm{~min}$ ); NMPC results (dotted line) and open loop modelling results (solid line); a) controlled variables ; b)- manipulated variables

Figure 7. Trajectories for the system controlled by QIHNMPC

Figure 8. Comparison between QIHNMPC and NMPC for $16^{\circ} \mathrm{C}$ disturbance in $T_{r}$; QIHNMPC results (solid line) and NMPC results (dotted line); (a)-controlled variables; (b)- manipulated variables

Figure 9. Performance of the MHE in the case of the $K_{c}$ disturbance $(0.9 \%$ step increase at $t=2 \mathrm{~min})$ - MHE results (dotted line) and open-loop modelling results (solid line)

Figure 10. Simulation results of the MHE-NMPC in the case of the $P_{5}$ disturbance (3\% step decrease at $\mathrm{t}=0 \mathrm{~min}$ ) 
Figure 11. CPU times required for the optimisation problems of the MHE and NMPC

Figure 12. Comparison between different FCCU control approaches in the presence of the pressure drop disturbance (27\% step decrease at $t=12 \mathrm{~min}$ ), the controlled variables; a) LMPC (dotted line);

NMPC (solid line) and b) PID control

Figure 13. Comparison between different FCCU control approaches in the presence of the pressure drop disturbance (27\% step decrease at $t=12 \mathrm{~min}$ ), the manipulated variables; (a) LMPC (dotted line); NMPC (solid line) and (b) PID control

\section{Table caption}

Table 1. Typical operating conditions and values obtained with the simulator 
Tables

Table 1. Typical operating conditions and values obtained with the simulator

\begin{tabular}{|c|c|c|c|c|}
\hline \multirow[t]{2}{*}{ Process variable } & \multirow[b]{2}{*}{$\begin{array}{c}\text { Measuring } \\
\text { unit }\end{array}$} & \multicolumn{2}{|c|}{ Industrial Plant Data } & \multirow[t]{2}{*}{ Value in simulator } \\
\hline & & $\begin{array}{c}\text { Minimum } \\
\text { value }\end{array}$ & $\begin{array}{c}\text { Maximum } \\
\text { value }\end{array}$ & \\
\hline Catalyst-to-Oil Ratio & - & 6.5 & 8.5 & 7.42 \\
\hline Reactor pressure & bar & 1.5 & 2.2 & 1.51 \\
\hline Regenerator pressure & bar & 1.7 & 2.4 & 1.7 \\
\hline Gasoline octane number & - & 0.9 & 0.96 & 0.94 \\
\hline Main fractionator pressure & bar & 0.9 & 1.5 & 1.34 \\
\hline Regenerator temperature & ${ }^{0} \mathrm{C}$ & 682 & 735 & 709.63 \\
\hline Reactor temperature & ${ }^{0} \mathrm{C}$ & 505 & 535 & 524.51 \\
\hline Raw material temperature & ${ }^{0} \mathrm{C}$ & 190 & 320 & 303.58 \\
\hline $\mathrm{CO}_{2}$ concentration in flue gas & $\%$ & 16 & 19 & 16.07 \\
\hline $\mathrm{O}_{2}$ concentration in flue gas & $\%$ & 0.8 & 2.5 & 1.02 \\
\hline Reactor Catalyst Inventory & tons & 35 & 50 & 39.76 \\
\hline Total Catalyst Inventory & tons & 175 & 195 & 191 \\
\hline
\end{tabular}

